\title{
Ecobehavioral Characteristics of Self-Contained High School Classrooms for Students with Severe Cognitive Disability
}

\author{
Jennifer A. Kurth, Ph.D. \\ University of Kansas \\ Kiara Born, M.S.Ed. \\ University of Kansas \\ Hailey Love, M.A. \\ University of Kansas
}

Citation: Kurth, J. A., Born, K., \& Love, H. (2016). Ecobehavioral characteristics of selfcontained high school classrooms for students with severe cognitive disability. Research and Practice for Persons with Severe Disabilities, 41(4), 227-243. doi:10.1177/1540796916661492 


\begin{abstract}
This study investigated educational experiences for students with significant cognitive disability (SCD) taught in self-contained high school classrooms. Nineteen students and nine teachers across five high schools and four school districts participated. A time-sampling method was used to describe the ecological, teacher, and student behaviors of these classrooms. Field notes were collected and analyzed as well. Results revealed students in these classrooms were often passively engaged and had few opportunities to learn from rigorous curriculum. Instructors engaged in few practices known to be effective in supporting the learning of students with SCD. Finally, the classrooms themselves were often distracting and demonstrated little evidence of specialized or effective instruction. Implications for teaching and research are included.

Keywords: Special education, severe disabilities, intellectual disability, self-contained classrooms
\end{abstract}




\section{Ecobehavioral Characteristics of Self-Contained High School Classrooms}

for Students with Severe Cognitive Disability

With the $40^{\text {th }}$ anniversary of the Individuals with Disabilities Education Act (IDEA), the context of education for students with significant cognitive disability (SCD), defined as the 1-2\% of students with intellectual disability who complete an alternate assessment and have support needs across domains (Kennedy, 2004), is undergoing changes in focus. Specifically, federal mandates (e.g., Every Student Succeeds Act, 2015) increasingly focus on accountability while simultaneously ensuring access to the general education curriculum (IDEA, 2004). The IDEA specifies children with disabilities should be educated with children without disabilities to the “maximum extent appropriate," thus establishing the general education setting as the preferred placement (34 C.F.R. Sec. 300.550). Concurrently, a growing body of research documents students with SCD can successfully learn general education academic content, ranging from literacy (Browder, Wakeman, Spooner, Ahlgrim-Delzell, \& Algozzine, 2006), to mathematics (e.g., Browder, Spooner, Ahlgrim-Delzell, Harris, \& Wakeman, 2008), science (Wood \& Allison, 2014), and social studies (Wood, Browder, \& Flynn, 2015).

In tandem with public policy and research related to academic instruction, further research documents the importance of educating students with SCD in general education contexts (e.g., Ryndak, Moore, Orlando, \& Delano, 2010). Students educated in inclusive settings have displayed similar or greater development in social competence (e.g., Freeman \& Alkin, 2000), communication (Rafferty, Piscitelli, \& Boetthcer, 2003), and reading and mathematics (Cole, Waldron, \& Majd, 2004) in comparison to students educated in selfcontained settings. Finally, inclusive classrooms have been shown to provide greater access to 
the general education curriculum (Jackson et al., 2009) and opportunities for academic engagement (Kurth \& Mastergeorge, 2012).

Despite the rights-basis of inclusive education established by IDEA and the benefits associated with inclusion, a dependence on self-contained settings persists for students with the most significant disabilities (Kurth, Morningstar, \& Kozleski, 2014; McLeskey, Waldron, Spooner, \& Algozzine, 2014). In fact, some argue there has been a "regression... or resignation toward, a self-contained setting as a viable placement for students with 'severe disabilities"” (Jackson, Ryndak, \& Wehmeyer, p. 176, 2008-2009). At its core, special education is intended to be both effective and special, employing a range of effective teaching strategies that are unique to the needs of a particular student (Cook \& Schirmer, 2003). Some interpret this need to deliver special and effective teaching as requiring special spaces with special teachers (e.g., Kauffman, Landrum, Mock, Sayeski, \& Sayeski, 2005). For example, Landrum, Tankersley, and Kauffman (2003) argue the specialness of special education "lies at least partially in the contextual variables including structure, intensity, precision, and relentlessness with which teachers deliver, monitor, and adapt instruction, [which] is surely beyond that which would be possible in a regular classroom” (p. 153). According to such perspectives, efforts to provide an appropriate education and attempts to provide an education in the general education classroom for students with disabilities conflict rather than intersect.

However, there is limited understanding of what actually occurs in these self-contained settings, including what is particularly special or effective about them. In one of the few observational studies of self-contained classrooms, Causton-Theoharis and colleagues (2011) observed K-12 self-contained classrooms in three states over seven years, with a total of 41 
student participants (with all but one of the students in grades K-6), concluding "we found it difficult to argue for fixing or improving these self-contained settings because everything we observed could have been transported to inclusive settings without compromising the education these students were receiving" (p. 73). Participants in this study included students with a range of disabilities beyond SCD. Recently, Pennington and Courtade (2015) observed self-contained classrooms serving students with moderate and severe intellectual disability to determine the extent to which teachers in these settings provided feedback and opportunities for students to respond. These researchers completed 35 observations of K-12 self-contained classrooms for 15-minutes each, with 45 students and 35 teachers participating. The grade levels of individual students are not reported. Pennington and Courtade (2015) found students were primarily taught in small group or one-to-one teaching arrangements, with instructors providing inadequate pacing to sustain optimal opportunities for students to respond, while students were engaged in primarily passive activities.

As articulated by Pennington and Courtade (2015), observational studies of selfcontained classrooms remain infrequent and limited, with more research needed to describe actual practices in educational contexts for students with SCD. Furthermore, as extant research has included large grade bands (K-12), with no study explicitly examining secondary settings, limited information is available with which to describe the unique characteristics of selfcontained secondary classrooms for students with SCD. Secondary programs are often focused on functional skills with instruction frequently occurring in community settings in order to prepare students for the transition to adulthood (Bouck, 2012; Conderman \& Katsiyannis, 2002). As a result, secondary education has a unique curricular focus and corresponding activities. 
Thus, given the unique emphasis of secondary special education on preparation for adulthood and the lack of research explicitly focusing on this age band, the purpose of this study is to address the following question: what are the educational experiences of youth with SCD who are educated in self-contained special education high school classrooms?

\section{Method}

\section{Participants and Settings}

Student Participants. The twenty-eight participants were 19 students and nine teachers. Student participants met the following criteria: (a) receiving special education services, (b) receiving instruction in a self-contained high school classroom for students with SCD for $80 \%$ or more of the school day, (c) parents provided consent to participate, and (d) students assented to participate. Students ranged in age from $15-18$ years ( $M=16.4$ years). Fourteen students were male, and student educational disability categories included intellectual disability $(n=9)$, autism spectrum disorder $(n=4)$, multiple disabilities $(n=5)$, and physical disability $(n=1)$. In all cases, students had concomitant intellectual disability in addition to another disability category, as reported by teachers in the recruitment process as well as placement in a classroom designated for students with SCD. To estimate student support needs and level of functioning, teachers completed a Likert-type rating scale ranging from 1 (no supports needed) to 5 (full physical assistance usually needed) to indicate the degree to which students needed supports for overall functioning (e.g., independent living) and learning new skills (see Soukup, Wehmeyer, Bashinski, \& Bovaird, 2007 for scale definitions). Ratings for student overall functioning support ranged from 2 to 5 (median $=3$ ), and ratings for student learning support ranged from 2 to 5 (median $=3)$. Nine student participants had complex communication needs $(\mathrm{CCN})$, defined as 
those students who researchers observed using, or appearing to require the use of, augmentative and alternative communication (AAC) to effectively communicate. Five students with $\mathrm{CCN}$ had access to symbolic AAC systems (e.g., voice output devices), while four communicated presymbolically using gestures and noises (e.g., pointing, crying). See Table 1 for student demographics.

Teacher Participants. Teacher participants met the following criteria: (a) teacher certification in low-incidence disabilities and (b) employed as the teacher of record in a selfcontained special education classroom serving students with the most significant disabilities. The nine teacher participants were all female. The mean age of the teachers was 46 years (range: 31 to 61 years). On the whole these were experienced teachers with 2-31 years of teaching experience $(M=19$ years, $S D=13.8)$. All teachers were certified to teach low-incidence ("severe") special education. Five teachers were also certified in high-incidence ("mild") special education and one teacher had general education teaching certification. See Table 2 for teacher demographics.

Settings. Observations occurred in five high schools (grades 9-12) located in four school districts in the Midwestern United States. The student population of the high schools ranged in size from $800-1900$, with a mean student body of 1380 . On average, $42 \%$ of students came from economically disadvantaged backgrounds (range: 15-81). Fifty-seven percent of the student population was White (range: 24-77) and 43\% non-White (Black, Hispanic, and other; range: 2376). Lastly, approximately $12 \%$ of the students in the schools had a disability (range: $7-20$ ).

Within the high schools, the classrooms serving students with SCD tended to be spacious and well appointed, and were often located in remote portions of the school building. Special 
education teacher caseload size ranged from 6-12 $(M=8.3)$. Each classroom had a large number of paid staff, ranging from 3-14 adults. While only students with SCD were present in most classrooms, students without known disabilities were also present in four classrooms. These students were enrolled in an 'interpersonal skills class' where students learned about disability and provided assistance to a peer with a disability. These peers without known disabilities $(n=$ 35) were present in six observations.

\section{Instrumentation}

Data were collected using a time sampling data collection system adapted from the ecobehavioral assessment systems software (EBASS; Greenwood, Carta, Kamps, Terry, \& Delquadri, 1994). The data collection system retained the three conceptual groupings (classroom ecology, teacher behavior, and student behavior) from the EBASS, with some variables redefined or changed (see Greenwood et al., 1994 and Lee et al., 2010 for EBASS variables). These modifications were made to reflect findings from other observations in the recent literature.

The conceptual grouping student behavior focuses on the activities of the participating focal student with SCD. Within this conceptual group, four categories and 30 variables exist. The first category examines types of academic behavior, including writing, reading, answering and asking questions about academic content, completing math, listening, watching, or transitioning to academic content, and non-academic behaviors (e.g., sorting materials, stuffing envelopes, completing puzzles). The second category describes the presence of any competing behaviors that could interfere with student learning, including repetitive behaviors that could serve a self-stimulatory function. The third category describes the student's partner during the 
activity, and the final category describes the requirements of the task at hand, including active (e.g., writing, manipulating items) and passive (e.g., watching, listening) engagement.

The conceptual group teacher behavior focuses on the activities of the person providing instruction at the time of the observation. Within this conceptual group, four categories and 25 variables were coded. The first category describes teaching activities, including asking questions, reading aloud, and lecturing. The second category describes the person(s) the teacher focused on during the observation, including the target student with SCD. The third category, teacher definition, describes the role of the person in charge of instruction. Finally, the last category (teacher approval) describes the type of feedback the instructor provided the student during the observation.

The final conceptual group, ecology, focuses on the characteristics of the learning environment. There are seven categories and 48 variables within this code. Instructional grouping describes the learning format, ranging from whole group (all students are engaged in the same task) to independent work. The physical arrangement category describes the layout of the classroom, from entire group (all students are grouped together) to individual (students are working alone in separate areas). The setting of instruction reflects the next ecology variable and includes 'no class,' meaning the location was a hallway, cafeteria, or other non-classroom setting. The type of activity occurring at the time of the observation describes the task variable, including other materials (e.g., puzzles, envelopes, sorting materials) and tasks requiring use of workbooks (e.g., books students write in) and readers (e.g., text books). Events occurring in the learning environment that could be distracting to a learner were coded in the distraction category, and the type of curriculum, including grade level (no changes), adapted curriculum (changed to 
reflect student need), alternate curriculum (separate special education curriculum), and absence of any curriculum (no curriculum).

Ultimately, a total of 15 categories across 103 variables in these three conceptual groupings constituted the data collection tool. A codebook (available from the first author) was developed operationally defining each variable, as well as examples and non-examples of each. Pilot testing occurred in a middle school in which 12 students and two special education teachers participated. Language arts, social studies, math, transitions, and adapted physical education were observed. Initially, the same student was observed for 15-minutes. Using a momentary time-sampling procedure, two observers collected data in each of the 15 categories every 60-s using the data collection table and codebook (see Greenwood, Carta, Kamps, \& Delquadri, 1997 for protocol). Following the 15-minute observations, the observers met and discussed coding issues. The codebook was edited as needed, and the data collection instrument itself was modified to reflect these changes. The observers then returned to the classroom and completed an additional round of 15-minute observations. This process continued for approximately 2 hours, until the authors no longer needed to make any adjustments to the instrument or codebook. The observers completed an additional two rounds of 45-minute observations to determine reliability. Interobserver agreement (IOA) was calculated using an interval method, in which the code entered by each observer for each interval (60-s) was compared and scored as agreement (same code) or disagreement (different code entered). The total number of agreements was then divided by the total number of intervals and multiplied by 100 to calculate IOA. Total IOA for both rounds of pilot testing was $89 \%$ and $93 \%$.

\section{Procedures}


Following university Human Subjects board approval, requests for participants were sent to school district administrators to observe high quality self-contained special education classrooms. High quality classrooms were specifically targeted as it was presumed the practices and strategies used in these classrooms were deemed effective for students with SCD. Previous research (e.g., Causton-Theoharis et al., 2011; Pennington \& Courtade, 2015) revealed substantial concerns with self-contained classrooms. To determine the extent to which these concerns simply reflect poor or even average classroom practices, we specifically recruited classrooms that were reputed as 'high quality.' However, researchers provided no measures of quality to ensure school-based indicators were used rather than any indicators supplied by the research team. Thus, it was left to the school district personnel to recruit participants from classes they considered "high quality." Following the selection of classrooms, informed consent for participation was obtained from parents, teachers, and students. Then, the special education teacher completed a demographic questionnaire about the student and themselves.

Upon arrival, the two observers introduced themselves to the special education teacher, briefly reviewed their purpose in observing high quality special education classrooms, and asked what activities would be occurring during the observation time. Observers then asked where they could sit or stand so they could easily hear and see the participants, yet not interfere with the activities in the classroom. Observers used the same paper form to document descriptive and reflective information from the observation. Reflective information included the thoughts, quotes, impressions, questions, ideas, or concerns of the observer. Descriptive information included details about the settings (including diagrams), actions, and behaviors observed. The Beepwatch IOS application (available from iTunes) was downloaded to each observer's cellular 
phone and set to vibrate every 60 -s, alerting the observer to collect data on the next conceptual group on the table. Thus, the observers attempted to be minimally invasive in terms of their positioning in the classrooms and in the materials they brought to each observation session (a cellular phone and an observation sheet). Each observer began the coding interval by starting the Beepwatch application and entering data that corresponded to the situation using the "look, record, and rest" pattern described in the EBASS protocol. Data collection terminated when new findings and settings ceased to emerge ( $\mathrm{n}=30$ observations).

All participants were observed in self-contained classrooms for, on average, 45 -minutes each (range: 39-48), the length of an average high school class period, during regular classroom activities using a momentary time-sampling method (described in the instrumentation section). Attempts were made to observe participates more than once, during different activities and at different times of day. This was accomplished for 11 participants (teacher/student dyads), but was not possible for the remaining eight.

Following the observations, the researchers asked teachers any follow-up questions to clarify what was observed. Next, the researchers met after each observation and engaged in a debriefing meeting, in which qualitative notes from the observation were generated, general impressions were discussed, and points for further follow-up were identified.

Inter-rater reliability was completed on 275 minutes of observation (approximately $20 \%$ of all observations) and ranged from $84-95 \%$ agreement, with a mean IOA of $91 \%$. In general, differences in coding were related to subtle differences in which each observer started her timer. As a result, the observers looked up to observe at slightly different times, resulting in coding different events. 


\section{Data Analysis}

All time sampling data were entered into SPSS V. 21, with the first two authors confirming the reliability of all data entered. Frequencies and percentages of ecobehavioral data were calculated. Additionally, composite variables were created by combining select variables into groups for comparison purposes (defined in the Results section). These composite variables were used to calculate independent samples t-tests to identify any significant differences when comparing all students and students with $\mathrm{CCN}$, and comparing all students and observations in which a peer without a known disability was present. Analysis of field notes suggested these groups (students with CCN and situations when peers without a known disability were present) as qualitatively different from other observations, and thus were further analyzed using inferential statistics.

Field notes were typed into MS Word documents for each participant and setting and analyzed using open-coding techniques (Strauss \& Corbin, 1990) in which data were independently analyzed for patterns related to observed practices and observer impressions. The first two authors then reviewed patterns together and identified themes; code words for these themes were created and field note data were examined for keywords. Investigator triangulation was completed in that all three authors compared codes applied to each line of field notes resulted, with an initial 92\% agreement between authors. The remaining disagreements were discussed and consensus reached.

\section{Results}

Students were observed in the settings in which they regularly participated, including: self-contained special education classrooms when only students with SCD were present $(82 \%$ of 
observation minutes), in special education classrooms when peers without a known disability were present ( $8 \%$ of observation minutes), transitioning through hallways from the classroom to the gymnasium to attend self-contained adapted physical education classes ('no class'; $1 \%$ of observation minutes), and in the gymnasium ( $9 \%$ of observation minutes). Hallways were included in the analysis because it constituted a natural opportunity for students with SCD to interact with, or at least be present with, their peers without known disabilities in the high school setting. Findings from the statistical analysis and coding of field notes indicate few effective and specialized characteristics of self-contained classrooms were evident in these observations.

\section{Student, Teacher, and Ecological Variables}

Descriptive statistics (frequencies and percentages) and independent samples t-tests for statistically significant composite variables are reported for student, teacher, and ecological variables. These include analyses for all participants in the sample ( $n=19$ students, $n=9$ teachers, $n=1,365$ minutes of observation), for students with the most complex communication needs ( $n=9 ; n=428$ observation minutes), and observations in which a peer without a known disability was present ( $n=5$ students, $n=237$ observation minutes).

Student Behavior Variables. Student behaviors describe the activities of the target student with SCD during the observation. Descriptive statistics are presented in Table 3 . The academic other variable (i.e., the target student is engaged in a non-grade aligned task, such as stuffing envelopes or completing a puzzle) was the most frequently observed student behavior for all students (39\%). Students were infrequently observed actively engaged in academic tasks, such as reading $(2 \%)$, writing $(5 \%)$, or math $(14 \%)$. Students generally demonstrated no competing behavior (defined as aggression, disruption, self-stimulatory behaviors, asleep, or 
non-compliance; 70\%) and frequently had no observed partner (52\%). Students were infrequently observed interacting with teachers $(5 \%)$ or peers $(11 \%)$. Independent samples t-tests of composite variables (active composite includes active, move, and play) revealed significant differences for students with $\mathrm{CCN}(M=3.09 ; S D=2.07 ; \mathrm{t}(26)=-2.41 ; p=.024)$ compared to students without $\mathrm{CCN}$ in the sample $(M=6.06 ; S D=4.30)$, demonstrating students without $\mathrm{CCN}$ were more likely to be active participants in learning than students with CCN.

Teacher Behavior Variables. Teacher behavior variables describe the behaviors of the person in charge of instruction at the time of the observation, as seen in Table 4. Special education teachers were most frequently observed engaging in no teaching behavior (e.g., working at a computer, talking to a paraprofessional; 47\%) and were seldom observed prompting, engaging in corrective feedback, or other indicators of systematic instruction. Teacher focus describes the person(s) the instructor was focused on during the observation. Teacher focus was most frequently 'adult' (paraprofessionals or related services providers; 39\%) as opposed to students (i.e., target, target plus other). Independent samples t-tests of composite teacher focus (target, target + other) and no teacher focus (no one) describe a significant difference for students with $\mathrm{CCN}(M=3.50 ; S D=1.28 ; \mathrm{t}(26)=-2.00 ; p=.01)$ compared to students without $\mathrm{CCN}(M=4.76, S D=1.81)$, suggesting teachers were less likely to interact with students with CCN in these observations. The person in charge of delivering instruction at the time of the observation was most frequently a paraprofessional (55\%), and classroom instructors on the whole were rarely observed showing approval (i.e., praise or reinforcement; 4\%) or disapproval (i.e., corrective feedback; 4\%) during the observations.

Ecology Variables. Ecology variables describe the context of the observation, as seen in 
Table 5. Students with SCD were most frequently observed in whole group instruction (i.e., the target student is receiving the same instruction as all other students in the setting; 48\%). The setting was most frequently representative of entire group work (i.e., all students are together; $42 \%$ ), and the setting of the observation was most frequently the self-contained special education classroom (83\%). Activities related to community living were most common (i.e., life skills such as use of money; 25\%), followed by reading (i.e., looking at or listening to printed materials; 18\%). The intended task for the observation was most frequently 'other materials' (i.e., puzzles, envelopes; 32\%). Furthermore, 'no task,' meaning no task was assigned at the time of the observation, occurred in $22 \%$ of the observations. Environmental distractions were frequently observed, including staff talking to one another (34\%) and other peers making loud noises (i.e., repetitive moaning or oral reciting behaviors; 15\%). However, distractions (staff talking, staff come and go, peer loud, peer restrained, peer off task) were significantly reduced when peers without known disabilities were present $(M=0.50 ; S D=0.548$; $\mathrm{t}(26)=-2.58 ; p=$ $.000)$ compared to observations when general education peers were not present $(M=4.55, S D=$ 3.77).

\section{Field Notes}

To supplement the time sampling observations, field notes were qualitatively analyzed and 3 themes were identified: (a) use of personnel, (b) classroom climate, and (c) segregation.

Use of Personnel. The use of personnel reflects staffing levels and the activities of personnel in these self-contained classrooms. Across observations, the mean staffing ratio was high, averaging one adult for every 1.7 students, ranging from 0.4 students per adult to 3 students per adult. In situations when students without known disabilities worked in small groups with 
students with disabilities, a paraprofessional was almost always assigned to the small group.

These paraprofessionals were frequently observed interacting with students and with one another, and were most often observed in close physical proximity to students with disabilities, while special education teachers were generally working at their desks.

Classroom Climate. The majority of observations occurred in self-contained special education classrooms, which were generally spacious. Most classrooms had a kitchenette, restroom, and laundry facilities within the classroom space. Few classrooms had desks; some had large tables, and a few had only chairs without any apparent workspace. Both classrooms and gymnasiums were characterized by a number of distractions, including adults entering and leaving, paraprofessionals and teachers interacting verbally with students, students making noises and pacing around the classrooms, and adults talking with one another about holidays, families, and weekend activities. Perhaps as a result of these on-going interactions, classrooms as a whole were friendly and welcoming, if not also distracting and off-task.

Segregation. Finally, the segregation theme describes the profound sense of autonomy and isolation of these classrooms. Each self-contained classroom was located in a remote section of the high school, sometimes on a separate wing or in the basement, physically separated from other classrooms. Special education teachers frequently reported, "nobody ever comes" to their classrooms. Further, natural opportunities for students with SCD to interact with their high school peers, including transitions between classes, were devoid of any physical or social contact with peers without known disabilities, as students with SCD transitioned between settings either before classes ended or after they had began. As a result, students with SCD were always the only students in the halls during transition times. Because students with SCD did not transition 
between classes at the same time as other students, they were denied any incidental opportunities for social or even physical inclusion. Furthermore, teachers reported having little access to collaborative relationships with other teachers or school activities by virtue of their physical location and very different working conditions (i.e., curriculum being taught, duties related to supervision of paraprofessionals, and the nature of their students' needs). Within class segregation was also apparent, as students with the most complex physical, health, learning, or communication needs were often separated from their more capable peers, and even moved to separate rooms for activities such as meals, stretching, and sleeping.

\section{Discussion}

This study sought to describe the educational experiences of students with SCD who were taught in self-contained high school classrooms. Participants included experienced teachers who were prepared to demonstrate practices they considered 'high quality.' Yet, we found students were largely engaged in passive activities taught by paraprofessionals, using curriculum that was ineffectively individualized with inadequate communication supports, in distracting classroom settings.

\section{Ecobehavioral Characteristics of Self-Contained High School Classrooms}

Analysis of teacher behaviors in these self-contained classrooms reveals teachers were often spending time on tasks other than instruction, including paperwork and general classroom and personnel management. In fact, special education teachers were the primary instructors in only $21 \%$ of observations. This low rate of academic instruction is similar to other investigations (e.g., Vannest, Hagan-Burke, Parker, \& Soares, 2011). Throughout the observations, special education teachers were primarily observed working at their desks, and to a lesser extent, 
teaching whole-group lessons. Paraprofessionals were observed providing the vast majority of instruction, echoing growing concerns about reliance on paraprofessionals to deliver instruction (e.g., Giangreco \& Broer, 2005).

Furthermore, students were provided few opportunities to respond, were passive observers in most instructional activities, and completed the same activities and worksheets as their peers without any evident individualization. Individualization is a hallmark of special education, and results in higher student engagement and fewer competing behaviors (Lee, Wehmeyer, Soukup, \& Palmer, 2010). Thus, failure to individualize and accommodate student participation in these settings was quite troubling.

Additionally, lack of communication supports in these classrooms was worrisome, as communication has been linked to positive post-school outcomes (Kleinert et al., 2002). Specifically, students with CCN in the present analysis interacted with teachers less often and were more likely to be engaged in a passive task than other students with SCD. These findings are consistent with other research demonstrating a lack of AAC use in both general and special education classrooms as well as missed opportunities to use AAC effectively (Kleinert et al., 2015).

That students were taught in highly distracting classrooms for the most part was also discouraging. Students, including those with SCD, presumably benefit from classrooms with clear expectations and few distractions to their learning (e.g., Kauffman et al., 2005). While all classrooms are indeed distracting at times, the degree of distraction in these settings was noteworthy. Adults often appeared off-task in their conversations with one another, and to a lesser extent, students were distracting to one another in their activities and vocalizations. 
Classrooms were infrequently arranged to support on-task work or collaborative interactions between students. Instead, the lack of physical structure appeared to impact the behaviors of staff and students alike, resulting in a distracting atmosphere that often was not conducive to productivity or learning. However, classroom distractions were significantly reduced when peers without known disabilities were present suggesting the presence of peers alters the behavior of teachers, paraprofessionals, and students with disabilities in meaningful ways.

In sum, student experiences in these self-contained classrooms were characterized by passive engagement, in distracting classrooms, and without evidence of effective instructional practices. These experiences were particularly pronounced for students with CCN. Given the observations occurred in classrooms district administrators considered to be of high quality and taught by experienced teachers, the effectiveness of self-contained classrooms must be evaluated.

Inadequacies of self-contained classrooms. Several factors were of specific concern in analyzing the time sampling and field notes of this study, each of which are reflective of the unique nature of self-contained, separate classrooms serving only students with SCD. First, students in these observations frequently had limited access to communication supports and partners. Others have also noted the infrequency with which students with CCN who use AAC interact with adults and peers in classroom settings (Chung, Carter, \& Sisco, 2012), suggesting that this is a widespread phenomenon. However, regular access to AAC and communication partners, along with a variety of other factors including linguistic and social skills, are necessary for communicative competence to develop for students with CCN (Light \& McNaughton, 2014). The dearth of communication partners in these self-contained settings, given low adult responsiveness and the limited communication skills of most if not all of the other students in the 
classroom, and the infrequency with which peers without a known disability were present, clearly demonstrates an inherent flaw of self-contained classrooms for students with SCD and CCN.

Furthermore, students were routinely grouped homogenously, often by severity of support need. Thus, those students with greatest needs in self-contained settings, particularly those with complex communication needs, had the least access to engaging instruction from highly qualified instructors. Moreover, students were educated in classrooms that were distracting during routines and activities that were often unstructured and apparently unplanned. It bears repeating that all classrooms are indeed distracting at times, but the types of distractions in self-contained settings suggest a design flaw with these settings. The large number of paid adult staff present resulted in climates in which adults carried on frequent conversations with one another, often during instructional activities. The task demands of these adults also required staff, including paraprofessionals and related services providers, to be entering and leaving the classroom frequently. Consequently, the rooms were characterized by active adults. The students themselves, however, were frequently passive observers of activities and instructional routines.

Finally, the inadequacies of these self-contained classrooms cannot be attributed to lack of resources. In fact, all classrooms were spacious with adequate materials. Further, the staffing levels in these classrooms indicated sufficient human resources. With growing support for the effectiveness of inclusive education for students with SCD (e.g., Cosier, Causton-Theoharis, \& Theoharis, 2013; Kleinert et al., 2015), the resources of these self-contained settings would likely be of better use distributed across high schools to support inclusive special education services 
(Giangreco, Suter, \& Hurley, 2013).

Ecobehavioral Characteristics of Inclusive Settings. While self-contained, separate classrooms pose inherent risks as described in the present investigation, similar ecobehavioral assessments of inclusive settings suggest substantively different environments and opportunities for students with SCD in these settings. For example, Soukup and colleagues (2007) observed 19 elementary students with intellectual and developmental disabilities using ecobehavioral assessment. They found students had access to the general education curriculum, working on grade level standards in $60-98 \%$ of intervals. Further, these students were provided supports and adaptations in $18-67 \%$ of all observations. Similarly, Wallace and colleagues (2002) completed observations in 118 inclusive classrooms, finding students with disabilities demonstrated high levels of academic engagement. They further found teachers spent $75 \%$ or more of their time actively involved in teaching, and student behavior was similar for those students who did and did not have a disability. Together, these findings suggest inclusive classrooms, when measured using a very similar rubric, confer significant potential ecobehavioral benefits to students with SCD.

\section{Limitations}

Several limitations in the present investigation must be acknowledged. First, observations occurred in a diverse set of high schools across four school districts in a relatively restricted geographic area with a small sample size of 19 students and 9 teachers, limiting the generalizability of findings reported here. Obtaining permission to observe classrooms was challenging, with several school districts declining our requests for observations. Thus, the participating high schools and districts may be qualitatively different than those who declined 
participation. Inclusion of additional school districts would allow for observation of a greater breadth of programming and instructional techniques. Second, our procedure limited observations to every $60 \mathrm{~s}$, resulting in the possibility that observers missed opportunities to record some events, thus potentially over- or under-estimating some events. Third, we were not able to complete multiple observations across different activities and settings with all participants. Doing so would have allowed us to better understand the impact of the lesson, setting, or activity on student and teacher behavior. Most students simply never left the selfcontained classroom, which precluded us from observing them in different settings or with different peers or instructors. At other times, student schedules varied based on student behavior, community based instruction trips, and staff availability (e.g., the absence of one or more paraprofessionals), making it difficult to anticipate what activities and settings we would actually be able to observe upon our arrival. Fourth, while all special education teachers were experienced and certified, their particular backgrounds and training is unknown. Specifically, knowing more about teachers' prior experience or training related to $\mathrm{CCN}$ may have explained the teachers' use of AAC and communication supports in general. As is, it is possible the teacher participants were simply unfamiliar with AAC and therefore did not use it. Fifth, information about student disability categories, IQ scores, and support needs relied on teacher report. We initially requested educational files for students to substantiate teacher reports, but found it impossible to gain school district permission to do so. Due to our interest in securing permission to observe classrooms, we refrained from this request and thus our reports related to student demographics rely on teacher report. It is possible that had we obtained student records, a more complete picture of student participants would have emerged. Finally, we provided no 
indicators of quality self-contained classrooms to personnel during our recruitment efforts. Had we done so, we may have recruited participants with more objective indicators of quality in place to serve as a baseline of quality.

\section{Implications for Future Research}

Limited observations of self-contained classrooms serving students with SCD have produced significant concerns about the effectiveness of segregated, self-contained settings (e.g., Causton-Theoharis et al., 2011; Pennington \& Courtade, 2015). However, these studies have been restricted by small sample sizes with broad age bands and tend to occur in limited geographic areas. To address these shortcomings in the extant literature, further research is needed across age bands, geographic, and demographic variables to better understand common practices and experiences in self-contained settings for students with SCD as existing findings lack generalizability.

Similarly, there remains a dearth of observational studies of students with SCD in inclusive settings (e.g., Carter et al., 2005; Soukup et al., 2007; Lee, Soukup, Little, \& Wehmeyer, 2009). A recent descriptive account of K-8 inclusive settings for students with SCD focused on classroom variables (e.g., interactions, teaching arrangements) and student engagement (Kurth, Lyon, \& Shogren, 2015), with these observations occurring in effective inclusive schools where students with SCD were reported to be successfully included. Observations of typical schools, including those with emerging inclusive practices, are needed to understand the common practices and experiences of students with SCD who are included across age bands and geographic areas.

Despite limited research, common features of self-contained classrooms are nevertheless 
emerging. Passive engagement of students taught in self-contained settings was frequent in the observations reported here and those completed by Pennington and Courtade (2015). Further research is needed to both describe the extensiveness of passive learning, and to develop strategies for improving active participation, using systematic instruction, for students with SCD and in particular for those students with SCD and CCN. Further corroborating findings from Pennington and Courtade (2015), students were observed receiving limited feedback (either positive or corrective) from instructors. Additional research targeting rates of feedback is needed across settings, as well as research to develop strategies to teach instructors how to provide effective and efficient feedback.

Given the limited observational studies of special education and inclusive classrooms, this exploratory study used a time sampling method to describe ecobehavioral characteristics of self-contained classrooms. This method was useful in allowing us to describe practices, but limited our ability to correlate teacher behavior, for example, with student behavior. Likewise, we were not able to describe the impact of ecological factors, such as classroom distractions, on student academic behaviors. Future research in which data are collected simultaneously across categories would be useful in describing the extent to which the presence or absence of behaviors or characteristics in one category impact others.

This investigation found students received little individualized instruction with limited access to communication supports. Additional research to develop strategies for promoting individualization, incorporation of communication supports in on-going classroom activities, and strategies for teaching a greater range of academic skills related to the general curriculum are needed. Further, efforts to bridge the research to practice gap related to these strategies is 
necessary (e.g., Fixsen, Blasé, Metz, \& Van Dyke, 2013). However, because full access to the general education curriculum cannot be attained when students are taught in separate settings (e.g., Kleinert et al., 2015), further research focused on teaching academic and communication skills in general education settings is needed.

Finally, research targeting methods to improve teaching opportunities and classroom ecology are needed. Investigations of strategies to increase teaching time, through such means as reallocating paraprofessionals to paperwork tasks thus freeing teachers to deliver instruction, would be useful to the field. Further, research describing classroom distractions in inclusive settings as compared to the emerging research described here and by Causton-Theoharis and colleagues (2011) is needed, along with research-based strategies for improving on-task behaviors for teaching staff and students across settings.

\section{Implications for Policy}

In summarizing the learning experiences of students with SCD in self-contained high school classrooms, we simply did not observe anything particularly special or effective about them, nor did we observe high-quality, enviable experiences of the students in these settings. While the quality of experiences varied across observations, these data cannot be used to justify further segregated education. In fact, these data, in partnership with other investigations of selfcontained special education settings (e.g., Cautson-Theoharis et al., 2011; Pennington \& Courtade, 2015), indicate the shortcomings of IDEA's LRE principle after 40 years of implementation and research.

While IDEA conveys a preference for inclusive settings, most students with SCD continue to be educated in self-contained settings (McLeskey et al., 2014). Thus, the promise of 
the LRE provision of IDEA remains unmet for millions of students with the most extensive support needs. Further, the ideals of high quality instruction from highly qualified teachers using appropriate curriculum and materials were further unmet; instead, students with SCD were engaged in separate activities divorced from the general education curriculum. These practices may reflect a failure to translate current special education research, which emphasizes the importance of inclusive context into practice (e.g., Cook \& Odom, 2013), but also adherence to a law that simply does not reflect the current science of disability and education. That is, the IDEA schools and teachers comply with continues to focus on labeling, remediating, and restricting. A law that focuses on achievement and membership for all students, along with the integration of special and general education resources and expertise, may better serve students with disabilities. Thus, while the observations described in this study occurred during the year of IDEA's $40^{\text {th }}$ anniversary, the findings of this study may inform the implementation of IDEA 2004 and direct the focus of a reauthorized of IDEA to improve access and experiences for students with SCD. 


\section{References}

Beepwatch IOS Application. (2014). Retrieved August 26, 2014, from https://itunes.apple.com/us/app/beepwatch-pro.../id741736974?mt=8

Bouck, E. C. (2012). Secondary students with moderate/severe intellectual disability: considerations of curriculum and post-school outcomes from the National Longitudinal Transition Study-2. Journal of Intellectual Disability Research, 56, 1175-1186. doi:10.1111/j.1365-2788.2011.01517.x

Browder, D., Wakeman, S., Spooner, F., Ahlgrim-Delzell, L., \& Algozzine, B. (2006). Research in reading instruction for individuals with significant cognitive disabilities. Exceptional Children, 72, 392-408.

Browder, D., Spooner, F., Ahlgrim-Delzell, L., Harris, A. A., \& Wakeman, S. (2008). A metaanalysis on teaching mathematics to students with significant cognitive disabilities. Exceptional Children, 74, 407-432.

Causton-Theoharis, J. N., Theoharis, G. T., Orsait, F., \& Cosier, M. (2011). Does self-contained special education deliver on its promises? A critical inquiry into research and practice. Journal of Special Education Leadership, 24, 61-78.

Chung, Y. C., Carter, E. W., \& Sisco, L. G. (2012). Social interactions of students with disabilities who use augmentative and alternative communication in inclusive classrooms. American Journal on Intellectual and Developmental Disabilities, 117, 349-367. doi:10.1352/1944-7558-117.5.349

Cole, C. L., Waldron, N. L., \& Majd, M. (2004). Academic progress of students across inclusive and traditional settings. Mental Retardation, 42, 136-144. doi: 10.1352/0047- 
6765(2004)42\%3C136:aposai\%3E2.0.co;2

Conderman, G., \& Katsiyannis, A. (2002). Instructional issues and practices in secondary special education. Remedial and Special Education, 23, 169-179. doi:http://dx.doi.org/10.1177/07419325020230030501

Cook, B. G., \& Odom, S. L. (2013). Evidence-based practices and implementation science in special education. Exceptional Children, 79, 135-144.

Cook, B. G., \& Schirmer, B. R. (2003). What is special about special education? Journal of Special Education, 37, 139-139. doi:10.1177/00224669030370030201

Cosier, M., \& Causton-Theoharis, J. (2011). Economic and demographic predictors of inclusive education. Remedial \& Special Education, 32, 496-505. doi:10.1177/0741932510362513

Every Student Succeeds Act, § P.L. 114-95 (2015).

Fixsen, D., Blasé, K., Metz, A., \& Van Dyke, M. (2013). Statewide implementation of evidencebased programs. Exceptional Children, 79, 213-230.

Freeman, S. F. N., \& Alkin, M. C. (2000). Academic and social attainments of children with mental retardation in general education and special education settings. Remedial and Special Education, 21, 3-18. doi:10.1177/074193250002100102

Giangreco, M., \& Broer, S. M. (2005). Questionable utilization of paraprofessionals in inclusive schools: are we addressing symptoms or causes? Focus on Autism \& Other Developmental Disabilities, 20, 10-26. doi:10.1177/10883576050200010201

Giangreco, M. F., Suter, J. C., \& Hurley, S. M. (2013). Revisiting personnel utilization in inclusion-oriented schools. The Journal of Special Education, 47, 121-132. doi:10.1177/0022466911419015 
Greenwood, C. R., Carta, J. J., Kamps, D., Terry, B., \& Delquadri, J. (1994). Development and validation of standard classroom observation systems for school practitioners: Ecobehavioral assessment systems software (EBASS). Exceptional Children, 61, 197. doi:10.1007/978-1-4612-3336-7_2

Individuals with Disabilities Education Improvement Act, H.R. 1350, Pub. L. No. P.L. 108-446 (2004).

Jackson, L., Ryndak, D. L., \& Wehmeyer, M. L. (2009). The dynamic relationship between context, curriculum, and student learning: A case for inclusive education as a researchbased practice. Research \& Practice for Persons with Severe Disabilities, 33-4, 175-195. doi: $10.2511 /$ rpsd.33.4.175

Kauffman, J. M., Landrum, T. J., Mock, D. R., Sayeski, B., \& Sayeski, K. L. (2005). Diverse knowledge and skills require a diversity of instructional groups: A position statement. Remedial and Special Education, 26, 2-6. doi:10.1177/07419325050260010101

Kennedy, C. (2004). Students with severe disabilities. In C. Kennedy \& E. Horn (Eds.), Including students with severe disabilities (pp. 3-14). Boston: Allyn \& Bacon.

Kleinert, H., Garrett, B., Towles, E., Garrett, M., Nowak-Drabik, K., Waddell, C., \& Kearns, J. (2002). Alternate assessment scores and life outcomes for students with significant disabilities: Are they related? Assessment for Effective Intervention, 28, 19-30. doi:0.1177/073724770202800103

Kleinert, H., Towles-Reeves, E., Quenemoen, R., Thurlow, M., Fluegge, L., Weseman, L., \& Kerbel, A. (2015). Where students with the most significant cognitive disabilities are taught: implications for general curriculum access. Exceptional Children, 81, 312-328. 
doi:10.1177/0014402914563697

Kurth, J. A., Lyon, K. J., \& Shogren, K. (2015). Supports provided to students with severe disabilities in inclusive schools: Lessons learned from schools implementing inclusive practices. Research \& Practice for Persons with Severe Disabilities, 40, 261-274. doi: $10.1177 / 1540796915594160$

Kurth, J. A., \& Mastergeorge, A. M. (2012). Impact of setting and instructional context for adolescents with autism. Journal of Special Education, 46, 36-48. doi:doi.org/10.1177/0022466910366480

Kurth, J. A., Morningstar, M. E., \& Kozleski, E. (2014). The persistence of highly restrictive special education placements for students with low-incidence disabilities. Research \& Practice for Persons with Severe Disabilities, 39, 227-239. doi: $10.1177 / 1540796914555580$

Landrum, T. J., Tankersley, M., \& Kauffman, J. M. (2003). What is special about special education for students with emotional or behavioral disorders? Journal of Special Education, 37, 148-156. doi:10.1177/00224669030370030401

Lee, S. H., Soukup, J. H., Little, T. D., \& Wehmeyer, M. (2009). Student and teacher variables contributing to access to the general curriculum for students with intellectual and developmental disabilities. The Journal of Special Education, 43, 29-44. doi:10.1177/0022466907313449

Lee, S.-H., Wehmeyer, M. L., Soukup, J. H., \& Palmer, S. B. (2010). Impact of curriculum modifications on access to the general education curriculum for students with disabilities.(Report). Exceptional Children, 76, 213-233. 
doi:10.1177/001440291007600205

Light, J., \& McNaughton, D. (2014). Communicative competence for individuals who require augmentative and alternative communication: A new definition for a new era of communication? Augmentative and Alternative Communication, 30, 1-18. doi:10.3109/07434618.2014.885080

McLeskey, J., Waldron, N. L., Spooner, F., \& Algozzine, B. (2014). What are effective inclusive schools and why are they important? In J. McLeskey, N. L. Waldron, F. Spooner, \& B. Algozzine (Eds.), Handbook of Effective Inclusive Schools (pp. 3-16). New York, NY: Routledge.

Pennington, R. C., \& Courtade, G. R. (2015). An examination of teacher and student behaviors in classrooms for students with moderate and severe intellectual disability. Preventing School Failure: Alternative Education for Children and Youth, 59, 40-47. doi:10.1080/1045988x.2014.919141

Rafferty, Y., Piscitelli, V., \& Boettcher, C. (2003). The impact of inclusion on language development and social competence among preschoolers with disabilities. Exceptional Children, 69, 467-480.

Ruppar, A. L. (2015). A preliminary study of the literacy experiences of adolescents with severe disabilities. Remedial and Special Education, 36, 235-245.

doi:10.1177/0741932514558095

Ryndak, D., Moore, M. A., Orlando, A. M., \& Delano, M. (2010). Access to the general curriculum: The mandate and the role of context in research-based practice. Research and Practice for Persons with Severe Disabilities, 33-4, 199-213. 
doi:10.2511/rpsd.33.4.199

Soukup, J. H., Wehmeyer, M. L., Bashinski, S. M., \& Bovaird, J. A. (2007). Classroom variables and access to the general curriculum for students with disabilities. Exceptional Children, 74, 101-120. doi:10.1177/001440290707400106

Strauss, A., \& Corbin, J. (1990). Basics of qualitative research: Grounded theory procedures and techniques. Newbury Park, CA: Sage.

Vannest, K. J., Hagan-Burke, S., Parker, R. I., \& Soares, D. A. (2011). Special education teacher time use in four types of programs. Journal of Educational Research, 104, 219-230. doi:10.1080/00220671003709898

Wallace, T., Reschly Anderson, A., Bartholomay, T., \& Hupp, S. (2002). An ecobehavioral examination of high school classrooms that include students with disabilities. Exceptional Children, 68, 345-359.

Wehmeyer, M. L., Lattin, D., \& Agran, M. (2001). Achieving access to the general curriculum for students with mental retardation: A curriculum decision-making model. Education and Training in Mental Retardation and Developmental Disabilities, 36, 327-342.

Wood, L., \& Allison, C. (2014). Teaching science comprehension to students with severe disabilities. DADD Online Journal, 1, 24-36.

Wood, L., Browder, D., \& Flynn, L. (2015). Teaching students with intellectual disability to use a self-questioning strategy to comprehend social studies text for an inclusive setting. Research \& Practice for Persons with Severe Disabilities, 40, 275-293. doi:10.1177/1540796915592155 
Table 1

Student Demographic Information

\begin{tabular}{|c|c|c|c|c|c|c|c|c|c|c|c|}
\hline $\begin{array}{l}\text { Participant }{ }^{\mathrm{a}} \\
\text { No. of } \\
\text { Observations }\end{array}$ & Age & Grade & $\begin{array}{c}\text { Gen- } \\
\text { der }\end{array}$ & School $^{\mathrm{a}}$ & $\begin{array}{l}\text { Primary } \\
\text { Disability }\end{array}$ & IQ Range $^{b}$ & Ethnicity & $\begin{array}{c}\text { Free } \\
\text { Lunch } \\
\text { Eligible }\end{array}$ & $\begin{array}{c}\text { Overall } \\
\text { Support } \\
\text { Rating }\end{array}$ & $\begin{array}{c}\text { Learning } \\
\text { Support } \\
\text { Rating }\end{array}$ & $\mathrm{CCN}$ \\
\hline Mary (1) & 18 & 12 & $\mathrm{~F}$ & Morris & ID & $45-60$ & 2 or more & $\mathrm{Y}$ & 3 & 3 & $\mathrm{~N}$ \\
\hline Cody (2) & 15 & 9 & M & Morris & ID & $45-60$ & 2 or more & $\mathrm{N}$ & 3 & 3 & $\mathrm{~N}$ \\
\hline Jake (2) & 16 & 10 & M & Morris & ID & Below 44 & White & $\mathrm{N}$ & 3 & 4 & $\mathrm{~N}$ \\
\hline Rebecca (2) & 15 & 10 & $\mathrm{~F}$ & Morris & ID & 45-60 & White & $\mathrm{Y}$ & 2 & 2 & $\mathrm{~N}$ \\
\hline Martin (1) & 15 & 10 & M & Hall & ID & $45-60$ & Black & $\mathrm{DK}$ & 3 & 3 & $\mathrm{~N}$ \\
\hline Alice (2) & 16 & 10 & $\mathrm{~F}$ & Hall & OI & $45-60$ & White & $\mathrm{Y}$ & 3 & 3 & $\mathrm{~N}$ \\
\hline Tom (2) & 16 & 10 & M & Trent & ASD & $45-60$ & Black & $\mathrm{Y}$ & 2 & 3 & $\mathrm{~N}$ \\
\hline Edward (1) & 15 & 9 & M & Trent & ASD & 61-69 & Hispanic & $\mathrm{Y}$ & 3 & 3 & $\mathrm{Y}$ \\
\hline Jordan (1) & 15 & 9 & M & Trent & MD & Below 44 & White & $\mathrm{Y}$ & 3 & 4 & $\mathrm{Y}$ \\
\hline Shane (2) & 17 & 11 & M & Trent & ID & $45-60$ & White & DK & 3 & 3 & $\mathrm{~N}$ \\
\hline Justin (1) & 16 & 9 & $\mathrm{M}$ & Oak & $\mathrm{MD}$ & Below 44 & Asian & $\mathrm{N}$ & 5 & 5 & Y \\
\hline Tyler (2) & 18 & 12 & M & Oak & ID & Below 44 & White & $\mathrm{Y}$ & 4 & 5 & Y \\
\hline Oscar (2) & 17 & 11 & M & Oak & MD & Below 44 & Hispanic & DK & 5 & 5 & $\mathrm{Y}$ \\
\hline $\operatorname{Kim}(1)$ & 18 & 12 & $\mathrm{~F}$ & Trent & MD & Below 44 & White & $\mathrm{Y}$ & 4 & 3 & $\mathrm{Y}$ \\
\hline John (2) & 16 & 10 & $\mathrm{M}$ & Trent & MD & Below 44 & White & $\mathrm{N}$ & 4 & 4 & $\mathrm{Y}$ \\
\hline Jeff (1) & 18 & 12 & M & Apple & ID & Below 44 & White & $\mathrm{N}$ & 4 & 4 & Y \\
\hline Lars (1) & 15 & 9 & M & Apple & ID & 45-60 & White & $\mathrm{N}$ & 2 & 3 & $\mathrm{~N}$ \\
\hline Vince (2) & 17 & 11 & M & Oak & ASD & $45-60$ & White & $\mathrm{N}$ & 2 & 3 & $\mathrm{~N}$ \\
\hline Cara (2) & 18 & 11 & $\mathrm{~F}$ & Oak & ASD & $45-60$ & White & $\mathrm{N}$ & 3 & 3 & $\mathrm{Y}$ \\
\hline
\end{tabular}

Note. CCN = Complex Communication Need; $\mathrm{F}=$ Female; $\mathrm{M}=$ Male; ID = Intellectual Disability; OI = Orthopedic Impairment; ASD = Autism Spectrum Disorders; MD = Multiple Disabilities; Y = Yes; N = No; DK = Don't Know; $2=$ Indirect or direct verbal prompts usually needed; $3=$ Gestures or modeling prompts usually needed; $4=$ Partial physical assistance usually needed; $5=$ Full physical assistance usually needed

${ }^{a}$ Pseudonym

${ }^{\mathrm{b}}$ As reported by special education teacher 
Table 2

Teacher Demographic Information

\begin{tabular}{lccccccc}
\multicolumn{1}{c}{ Participant $^{\mathrm{a}}$} & Age & $\begin{array}{c}\text { Years Teaching } \\
\text { Experience }\end{array}$ & Gender & School $^{\text {a }}$ & $\begin{array}{c}\text { Caseload } \\
\text { Size }\end{array}$ & $\begin{array}{c}\text { Credentials and } \\
\text { Degrees Held }^{\text {b }}\end{array}$ & $\begin{array}{c}\text { Course Taught } \\
\text { Observed }^{c}\end{array}$ \\
\hline Ms. White & 59 & 31 & F & Morris & 9 & 3,5 & SPED \\
Ms. Green & 54 & 26 & F & Morris & 9 & 2,4 & SPED \\
Ms. Yellow & 48 & 21 & F & Morris & 8 & 2,5 & Adaptive PE \\
Ms. Brown & 30 & 2 & F & Hall & 12 & 3,5 & SPED \\
Ms. Blue & 61 & 39 & F & Trent & 7 & 3,4 & SPED \\
Ms. Orange & 40 & 15 & F & Trent & 6 & 2,5 & SPED \\
Ms. Red & 43 & 14 & F & Oak & 7 & $1,2,3,5$ & SPED \\
Ms. White & 32 & 4 & F & Oak & 9 & $2,3,5$ & SPED \\
Ms. Purple & 31 & 5 & F & Apple & 8 & $2,3,5$ & SPED \\
\hline
\end{tabular}

Note. $\mathrm{F}=$ Female; $1=$ General Education; 2 = High Incidence Special Education; 3 = Low Incidence Special Education; $4=$ Bachelor's Degree; 5 = Masters Degree; SPED = Self-Contained Special Education; PE = Physical Education

${ }^{a}$ Pseudonym 
Table 3

Descriptive Statistics of Student Behavior

\begin{tabular}{|c|c|c|c|c|c|c|}
\hline \multirow[t]{2}{*}{ Student Behavior Codes } & \multicolumn{2}{|c|}{$\begin{array}{l}\text { Total Frequency } \\
\qquad(N=364)\end{array}$} & \multicolumn{2}{|c|}{$\begin{array}{c}\mathrm{CCN} \\
(N=127)\end{array}$} & \multicolumn{2}{|c|}{$\begin{array}{l}\text { Peer Presen } \\
\quad(N=66)\end{array}$} \\
\hline & $\mathrm{n}$ & $(\%)$ & $\mathrm{n}$ & $(\%)$ & $\mathrm{n}$ & $(\%)$ \\
\hline \multicolumn{7}{|l|}{ Student Academic Behavior } \\
\hline Academic Other & 141 & (39) & 60 & (47) & 26 & (39) \\
\hline Watch, Listen, Transition & 95 & (26) & 40 & (32) & 25 & (38) \\
\hline Math & 52 & (14) & 6 & (5) & 3 & (5) \\
\hline Technology & 30 & (8) & 13 & (10) & 6 & (9) \\
\hline Writing & 20 & (5) & 1 & (1) & 0 & \\
\hline On A Break & 12 & (3) & 5 & (4) & 1 & (2) \\
\hline Talk Academic & 6 & (2) & 2 & (2) & 5 & (8) \\
\hline Read Silent & 5 & (1) & 0 & & 0 & \\
\hline Read Aloud & 3 & (1) & 0 & & 0 & \\
\hline \multicolumn{7}{|l|}{ Student Competing Behavior } \\
\hline No Competing & 254 & (70) & 84 & (66) & 43 & $(65)$ \\
\hline Self-Stimulate & 52 & (14) & 34 & (27) & 18 & (27) \\
\hline Look Around & 38 & (10) & 5 & (4) & 1 & (2) \\
\hline Non-Comply & 14 & (4) & 3 & (2) & 2 & (3) \\
\hline Disruptive & 3 & (1) & 0 & & 0 & \\
\hline Asleep & 2 & (1) & 1 & (1) & 2 & (3) \\
\hline Aggression & 1 & (0) & 0 & & 0 & \\
\hline Talk Inappropriate & 1 & (0) & 0 & & 0 & \\
\hline Self-Abuse & 0 & & 0 & & 0 & \\
\hline \multicolumn{7}{|l|}{ Student Partner } \\
\hline No Partner & 189 & (52) & 62 & (49) & 25 & $(38)$ \\
\hline Paraprofessional & 117 & (32) & 60 & (47) & 14 & (21) \\
\hline Peer With Disability & 26 & (7) & 0 & & 13 & (20) \\
\hline Special Education Teacher & 19 & (5) & 5 & (4) & 1 & (2) \\
\hline Peer without Disability & 13 & (4) & 0 & & 14 & (21) \\
\hline General Education Teacher & 0 & (0) & 0 & & 0 & \\
\hline \multicolumn{7}{|l|}{ Student Task } \\
\hline Active & 136 & $(37)$ & 14 & (12) & 22 & (33) \\
\hline Passive & 123 & $(34)$ & 66 & $(56)$ & 22 & (33) \\
\hline Off-Task & 84 & (23) & 33 & $(28)$ & 19 & (29) \\
\hline Move & 21 & (6) & 4 & (3) & 3 & (5) \\
\hline Play & 0 & & 0 & & 0 & \\
\hline Raise Hand & 0 & & 0 & & 0 & \\
\hline
\end{tabular}

Note. $\mathrm{CCN}=$ Complex Communication Need 
Table 4

Descriptive Statistics of Teacher Behavior

\begin{tabular}{|c|c|c|c|c|c|c|}
\hline Teacher Behavior Codes & \multicolumn{2}{|c|}{$\begin{array}{l}\text { Total Frequency } \\
\qquad(N=364)\end{array}$} & \multicolumn{2}{|c|}{$\begin{array}{c}\mathrm{CCN} \\
(N=127)\end{array}$} & \multicolumn{2}{|c|}{$\begin{array}{l}\text { Peers Present } \\
\quad(N=66)\end{array}$} \\
\hline \multicolumn{7}{|l|}{ Teacher Behavior } \\
\hline No Behavior & 171 & $(47)$ & 63 & $(50)$ & 29 & (44) \\
\hline Talk Academic & 69 & (19) & 29 & (23) & 23 & (35) \\
\hline Ask Question & 56 & (15) & 14 & (11) & 8 & (12) \\
\hline Make Command & 46 & (13) & 13 & (10) & 5 & (8) \\
\hline Sing & 8 & (2) & 7 & (6) & 0 & \\
\hline Prompt & 7 & (2) & 0 & & 0 & \\
\hline Feedback & 2 & (1) & 1 & (1) & 1 & (2) \\
\hline Read Aloud & 5 & (1) & 0 & & 0 & \\
\hline Threaten & 0 & & 0 & & 0 & \\
\hline Seclude & 0 & & 0 & & 0 & \\
\hline Restrain & 0 & & 0 & & 0 & \\
\hline \multicolumn{7}{|l|}{ Teacher Focus } \\
\hline Adult & 143 & (39) & 35 & $(28)$ & 23 & $(35)$ \\
\hline No One & 105 & (29) & 55 & (43) & 20 & (30) \\
\hline Target + Other & 67 & (18) & 32 & $(25)$ & 17 & (26) \\
\hline Target & 49 & (13) & 5 & (4) & 6 & (9) \\
\hline \multicolumn{7}{|l|}{ Teacher Definition } \\
\hline Paraprofessional & 200 & $(55)$ & 15 & (12) & 6 & (9) \\
\hline Special Education Teacher & 78 & (21) & 77 & (61) & 31 & $(47)$ \\
\hline Related Services & 48 & (13) & 35 & $(28)$ & 0 & \\
\hline General Education Teacher & 18 & (5) & 0 & & 0 & \\
\hline Peer Tutor & 11 & (3) & 0 & & 29 & $(44)$ \\
\hline Substitute & 1 & (0) & 0 & & 0 & \\
\hline Student Teacher & 0 & & 0 & & 0 & \\
\hline \multicolumn{7}{|l|}{ Teacher Approval } \\
\hline Neither & 334 & (92) & 124 & (98) & 64 & (97) \\
\hline Approve & 16 & (4) & 3 & (2) & 2 & (3) \\
\hline Disapprove & 14 & (4) & 0 & & 0 & \\
\hline
\end{tabular}

Note. $\mathrm{CCN}=$ Complex Communication Need 
Table 5

Ecology Descriptive Statistics

\begin{tabular}{|c|c|c|c|c|c|c|}
\hline \multirow[t]{2}{*}{ Ecology Codes } & \multicolumn{2}{|c|}{$\begin{array}{l}\text { Total Frequency } \\
\qquad(N=364)\end{array}$} & \multicolumn{2}{|c|}{$\begin{array}{c}\mathrm{CCN} \\
(N=127)\end{array}$} & \multicolumn{2}{|c|}{$\begin{array}{c}\text { Peer Present } \\
\quad(N=66)\end{array}$} \\
\hline & $\mathrm{n}$ & $(\%)$ & $\mathrm{n}$ & $(\%)$ & $\mathrm{n}$ & $(\%)$ \\
\hline \multicolumn{7}{|l|}{ Instructional Grouping } \\
\hline Whole Group & 173 & $(48)$ & 62 & (49) & 38 & $(58)$ \\
\hline Small Group & 87 & $(24)$ & 40 & (31) & 28 & (42) \\
\hline Individual & 77 & (21) & 23 & (18) & 0 & \\
\hline Independent & 27 & (7) & 2 & (2) & 0 & \\
\hline \multicolumn{7}{|l|}{ Physical Arrangement } \\
\hline Entire Group & 154 & $(42)$ & 65 & $(51)$ & 24 & (36) \\
\hline Divided Group & 129 & (35) & 27 & (21) & 42 & (64) \\
\hline Individual & 81 & (22) & 35 & (28) & 0 & \\
\hline \multicolumn{7}{|l|}{ Setting } \\
\hline Special Education & 322 & (89) & 101 & (80) & 66 & $(100)$ \\
\hline Gym & 31 & (9) & 18 & (14) & 0 & \\
\hline No Class & 11 & (3) & 8 & (6) & 0 & \\
\hline \multicolumn{7}{|l|}{ Activity } \\
\hline Community Living & 92 & (25) & 37 & (29) & 63 & (95) \\
\hline Reading & 66 & (18) & 18 & (14) & 0 & \\
\hline Math & 32 & (9) & 4 & (3) & 0 & \\
\hline Music & 32 & (9) & 18 & (14) & 0 & \\
\hline Physical Education & 32 & (9) & 19 & (15) & 0 & \\
\hline Art & 31 & (9) & 0 & & 0 & \\
\hline Independent Living & 30 & (8) & 13 & (10) & 3 & (5) \\
\hline Gross Motor & 16 & (4) & 16 & (13) & 0 & \\
\hline Writing & 11 & (3) & 0 & & 0 & \\
\hline Pre-Vocational & 8 & (2) & 0 & & 0 & \\
\hline Fine Motor & 6 & (2) & 2 & (2) & 0 & \\
\hline Spelling & 4 & (1) & 0 & & 0 & \\
\hline Social Studies & 4 & (1) & 0 & & 0 & \\
\hline Science & 0 & & 0 & & 0 & \\
\hline \multicolumn{7}{|l|}{ Task } \\
\hline Other Materials & 115 & (32) & 31 & (24) & 6 & (9) \\
\hline No Task & 80 & (22) & 53 & (42) & 16 & (24) \\
\hline Computer & 52 & (14) & 23 & (18) & 6 & (9) \\
\hline Discussion & 33 & (9) & 3 & (2) & 22 & (33) \\
\hline Listen & 24 & (7) & 10 & (8) & 7 & (11) \\
\hline Readers & 24 & (7) & 6 & (5) & 0 & \\
\hline Workbooks & 19 & (5) & 0 & & 9 & (14) \\
\hline Paper \& Pencil & 17 & (5) & 1 & (1) & 0 & \\
\hline
\end{tabular}




\begin{tabular}{|c|c|c|c|c|c|c|}
\hline \multicolumn{7}{|l|}{ Distraction } \\
\hline No Distraction & 173 & (39) & 71 & $(48)$ & 50 & $(72)$ \\
\hline Staff Talking & 148 & (34) & 26 & (18) & 3 & (4) \\
\hline Peer Loud & 68 & (15) & 30 & (20) & 10 & (14) \\
\hline Staff Come \& Go & 28 & (6) & 18 & (12) & 4 & (6) \\
\hline Peer Off Task & 23 & (5) & 2 & (1) & 0 & \\
\hline Peer Restrained & 0 & & 0 & & 0 & \\
\hline \multicolumn{7}{|l|}{ Curriculum } \\
\hline Alternate & 232 & (64) & 50 & (39) & 52 & (81) \\
\hline No Curriculum & 120 & (33) & 72 & (57) & 12 & (19) \\
\hline Adapted & 12 & (3) & 5 & (4) & 0 & \\
\hline Grade Level & 0 & & 0 & & 0 & \\
\hline
\end{tabular}

Note. $\mathrm{CCN}=$ Complex Communication Need 